\title{
Low-molecular-weight, fatty-acid esters as potential low-temperature drilling fluids for ice coring
}

\author{
Huiwen XU, ${ }^{1}$ Lili HAN, ${ }^{2}$ Pinlu CAO, ${ }^{1}$ Mingyi GUO, ${ }^{1}$ Junjie HAN, ${ }^{1}$ Dahui $\mathrm{YU},{ }^{1}$ \\ Pavel TALALAY ${ }^{1}$ \\ ${ }^{1}$ Polar Research Center, Jilin University, Changchun, China \\ E-mail: ptalalay@yahoo.com \\ ${ }^{2}$ Institute of Exploration Techniques, Langfang, China
}

\begin{abstract}
A challenge for future deep-ice coring in central Antarctica is to identify an appropriate inert drilling fluid with no undesirable physical or chemical characteristics. The drilling fluids currently in use (kerosene-based fluids with density-increasing additives, ethanol and $n$-butyl acetate) are not intelligent choices for the future from safety, environmental and some technological standpoints. Recently proposed drilling fluids based upon $\mathrm{ESTISOL}^{\mathrm{TM}}$ have high viscosity at low temperatures, which severely limits their application in cold environments. This paper presents our research into the application of low-molecular-weight, fatty-acid esters (FAEs), substances commonly used in the fragrance and flavoring industries. According to available data, selected FAEs are not hazardous to human health. Considering density requirements alone, ethyl butyrate and $n$-propyl propionate best meet our present needs. The viscosities of these two chemicals are also the lowest among studied FAEs, not exceeding $4 \mathrm{mPa}$ at temperatures down to $-60^{\circ} \mathrm{C}$. Both compounds are highly volatile, and insoluble in water. Such properties are attractive, but the applicability of FAEs to deep, cold, ice drilling can be evaluated only after field-based, practical experiments in test boreholes.
\end{abstract}

KEYWORD: ice coring

\section{INTRODUCTION}

Plans to drill in the central Antarctic ice sheet are being formulated by various national and international groups (e.g. Gamburtsev subglacial drilling project; US intermediate drilling at South Pole; Rapid Access Ice Drilling) for diverse purposes such as the study of changing climate, glacier dynamics, ancient life and the subglacial environment. In deep boreholes, the main functions of the drilling fluid are the exertion of balancing hydrostatic pressure to maintain the stability of the borehole, and the transportation of cuttings (or melted water) from the advancing face. Typically, the cuttings or meltwater are temporarily stored in a chamber within the drill, which is periodically withdrawn to the surface and emptied.

A number of special, low-temperature drilling fluids (kerosene-based fluids with density-increasing additives, ethanol and $n$-butyl acetate) have been proposed for ice coring, but not all of them are intelligent choices from safety, environmental and some technological standpoints (Talalay and Gundestrup, 2002; Gerasimoff, 2003). We contend that the probable next wave of ice-drilling-fluid evolution will arise through the introduction of ESTISOL ${ }^{\mathrm{TM}}$ esters, compounds that are classified as non-hazardous substances (Talalay and others, 2014a).

Danish specialists from the Centre for Ice and Climate, University of Copenhagen, recently chose a mixture of ESTISOL $^{\text {TM }} 240$ ester and COASOL $^{\text {TM }}$ for laboratory and field testing (Sheldon and others, 2014). Both liquids are characterized by low vapor pressure, almost no odor, low toxicity and good biodegradability. The main disadvantage of this mixture is its very high viscosity $\left(\sim 30 \mathrm{cSt}\right.$ at $\left.-35^{\circ} \mathrm{C}\right)$ which increases the travel time of the drill and, therefore, the total drilling time.
Another promising product of this type is the aliphatic synthetic ester ESTISOL ${ }^{\text {TM }}$ 140, a clear fluid with fruit-like odor that is immiscible with water (Talalay and others, 2014a). ESTISOL ${ }^{\text {TM }} 140$ mixtures with ESTISOL ${ }^{\text {TM }} 165$ and ESTISOL $^{\text {TM }}$ F2887 have suitable density and viscosity at low temperatures, and field tests have proved ESTISOL ${ }^{\text {TM }} 140$ applicable to deep drilling of ice sheets. The viscosity of ESTISOL $^{\text {TM }} 140$-based fluids can be considered reasonable at borehole temperatures down to $-50^{\circ} \mathrm{C}$, but the viscosity at lower temperatures is excessive ( $>25 \mathrm{cSt}$ ).

Sometime ago it was also proposed to use the lowmolecular-weight dimethylsiloxane oils as drilling fluid (Talalay, 2007). The density of these oils is suitable for compensation of ice overburden pressure, and their viscosity allows 'normal' performance of the drill's lowering/hoisting operations, even in very cold ice. They are inert to ice, metals, most plastics and elastomers, and have satisfactory volatility. They have no unpleasant odor, and low toxicity. Grades and price vary significantly depending on suppliers, and they cost more than some alternatives (minimum price currently $\sim U S \$ 7.5 \mathrm{~kg}^{-1}$ ).

The search for one or more new, environmentally friendly, relatively cheap drilling fluids for coring in central Antarctica remains one of the most pressing challenges for future drilling projects. This paper presents our investigation of a small selection of low-molecular-weight, fatty-acid esters that meet the requirements for low-temperature drilling fluids.

\section{DESIRABLE PROPERTIES}

The ideal low-temperature drilling fluid would simultaneously have several desirable and somewhat conflicting properties. 
Density is perhaps the most important fluid property, as pressure throughout the fluid column should be sufficient to prevent plastic deformation and borehole closure. On the other hand, excess density and pressure is undesirable because the borehole will then expand. As a first approximation, the desirable, average fluid density in the borehole can be estimated as (Talalay and others, 2014b)

$$
\bar{\rho}_{\mathrm{fl}}=\frac{\bar{\rho}_{\text {ice }}\left(z-H_{1}\right)}{k_{\mathrm{c}}\left(z-H_{0}\right)}
$$

where $\bar{\rho}_{\text {ice }}$ is the average ice density $\left(\mathrm{kg} \mathrm{m}^{-3}\right), \mathrm{z}$ is borehole depth $(\mathrm{m}), H_{1}$ is the 'firn correction' factor which accounts for the reduced density of snow and firn at the top of the ice sheet (its value depends on the ice accumulation conditions (e.g. Tchistyakov and others (1994) suggested $H_{1}=34 \mathrm{~m}$ at Vostok station, East Antarctica)), $k_{\mathrm{c}}$ is the empirical coefficient accounting for the fluid compressibility $\left(k_{\mathrm{c}} \sim 1.01\right.$ for depths of $2000-3000 \mathrm{~m}$ in cold ice sheets) and $H_{0}$ is the fluid level in the borehole $(\mathrm{m})$.

Taking the average density of ice $920-923 \mathrm{~kg} \mathrm{~m}^{-3}$ and fluid level in the borehole $80-100 \mathrm{~m}$ below the present-day snow surface, we assume that the average fluid density should be in the range $925-935 \mathrm{~kg} \mathrm{~m}^{-3}$ if the final borehole depth is $3000 \mathrm{~m}$. This value must be maintained as the average fluid density at the average borehole temperature (in central Antarctica, $T=-30 \pm 5^{\circ} \mathrm{C}$ ).

Viscosity of the fluid influences the winching power requirements, travel time of the drill string and the total drilling time. There are two alternative ways to achieve the desired drill lowering rate: either a low-viscosity fluid must be used, or boreholes with a larger clearance between drill and borehole walls must be drilled to decrease viscous drag. Lower viscosities are preferred because a larger-diameter borehole has the disadvantages of increased cuttings and higher power input.

The drill is lowered to the bottom of the borehole, driven by gravity alone. This method is very simple and energyefficient, but the falling velocity depends on the viscous drag exerted on the drill as it sinks. It is generally recognized that low viscosity (less than 5-10 mPa s; Talalay and Gundestrup, 1999) is one of the essential requirements for ice-drilling fluids. These values are probably conservative, as experience in the NEEM (North Greenland Eemian Ice Drilling) borehole showed a free lowering rate of at least $1.0 \mathrm{~m} \mathrm{~s}^{-1}$ at clearance $7 \mathrm{~mm}$ using a mixture of ESTISOL ${ }^{\mathrm{TM}} 240$ and $\mathrm{COASOL}^{\mathrm{TM}}$ with viscosity of 20-25 mPa s (personal communication from S. Hansen, 2011). Thus, the acceptable viscosity of the drilling fluid may prove to be as high as $20-25 \mathrm{mPa}$, subject to future study.

Freezing point of the fluid must, of course, be higher than the minimal temperature in the borehole. The annual average temperatures in central Antarctica (and thus the minimal borehole temperatures) at $10 \mathrm{~m}$ depth are in the range -50 to $-58^{\circ} \mathrm{C}$ (King and Turner, 1997); this can be taken as the minimum operating temperature for lowtemperature drilling fluids.

Stability of the drilling fluid should be sufficiently great that the fundamental properties remain unchanged during storage, transportation and use in the borehole.

Reactivity of the drilling fluid should be low, i.e. essentially inert. Drilling fluid should be non-aggressive to drill and cable components, stable to water, air, oxygen, metals and wood, compatible with most plastics and elastomers, and completely un-reactive with ice.
The matter of volatility is not simple. On the one hand, the high volatility of drilling fluid raises human-health and firesafety questions. For liquids with a high rate of vaporization it is necessary to organize careful control of air contamination so as to ensure that exposure-threshold limits and minimal inflammable concentration are observed. From this point of view, it is preferable to use fluid with a low rate of vaporization. On the other hand, there are benefits to high volatility: workplace and clothes become clear of liquid contamination after a short time, and ice-core processing is easier.

Cost of the fluid should be relatively low, and fluid should be readily available from commercial sources near the site of drilling operations; the effective cost results not so much from the initial purchase of the drilling fluid, but from its transportation to Antarctica. Using the drilling fluid also requires a costly processing system including mixing devices, pumps, chip recovery system, ventilation, etc. Most of the processing equipment is the same for different types of fluid, but distinctions exist. For example, mixing devices are not needed for single-component drilling fluids such as $n$-butyl acetate.

Toxicological and environmental properties of the drilling fluids have become the key point for the forthcoming drilling projects in Antarctica because recently used fluids are toxic and environmentally hazardous substances (Talalay and others, 2014a). The ideal drilling fluid would be non-toxic to humans and biodegradable.

\section{LOW-MOLECULAR-WEIGHT FATTY ACID ESTERS}

Esters consist of an organic or inorganic acid in which at least one $-\mathrm{OH}$ (hydroxyl) group is replaced by an -O(alkoxy) group. Fatty-acid esters (FAEs) result from the bonding of a fatty acid with an alcohol. They are widely distributed in nature. FAEs are typically fragrant, and those with low enough molecular weight have sufficient volatility for common use in fragrances; they are often found in 'essential oils' and pheromones. Some FAEs find application as solvents in the nitrocellulose and cellulose industry.

Low-molecular-weight FAEs can have hazardous properties (e.g. n-butyl acetate that was used to complete two deep drilling projects at Summit, Greenland (GISP2 Project, $3053 \mathrm{~m})$, and Dome F, Antarctica $(3035 \mathrm{~m})$, presenting an ongoing liability from a fire safety and acute- and chronichealth-hazard standpoint. The main risk posed by $n$-butyl acetate as a drilling fluid is to the physical and mental health of the people working at the drilling site.

Not all low-molecular-weight FAEs are harmful to human beings and the environment. Many of them occur naturally in plants and fruits. Chemically synthesized, they find commercial application in artificial flavoring because they resemble, for example, orange or pineapple juice and within certain limitations cause no harm to the human body (Surburg and Panten, 2006). Thus, we selected five nonHAP (i.e. not listed as hazardous air pollutants), lowmolecular-weight FAEs and studied their applicability as low-temperature drilling fluids for ice-coring in central Antarctica, namely (Table 1): (1) ethyl butyrate, (2) $n$-propyl propionate, (3) n-butyl butyrate, (4) n-amyl butyrate and (5) hexyl acetate.

Ethyl butyrate (also known as ethyl butanoate or butyric ether) has a fruity odor, similar to pineapple. It is one of the most commonly used chemicals in flavors and fragrances. It is used to enhance orange juice and the flavoring of 
Table 1. Typical physical properties of selected low-molecular-weight FAEs

\begin{tabular}{|c|c|c|c|c|c|}
\hline Property & Ethyl butyrate & $n$-Propyl propionate & n-Butyl butyrate & n-Amyl butyrate & Hexyl acetate \\
\hline CAS No.* & $105-54-4$ & $106-36-5$ & $109-21-7$ & $540-18-1$ & $142-92-7$ \\
\hline Molecular weight $\left(\mathrm{g} \mathrm{mol}^{-1}\right)$ & 116.16 & 116.16 & 144.21 & 158.24 & 144.21 \\
\hline Freezing point $\left({ }^{\circ} \mathrm{C}\right)$ & -93.3 & -76.0 & -91.5 & -73.2 & -80.9 \\
\hline Boiling point $\left({ }^{\circ} \mathrm{C}\right)$ & 121.3 & 122.4 & 166.6 & 186.4 & 171.5 \\
\hline Dynamic viscosity at $20^{\circ} \mathrm{C}\left(\mathrm{mPa} \mathrm{s}^{-1}\right)$ & 0.71 & 0.70 & NA & NA & NA \\
\hline Vapor pressure at $20^{\circ} \mathrm{C}(\mathrm{kPa})$ & 1.51 & 1.43 & 0.24 & 0.08 & 0.19 \\
\hline Flash point $\left({ }^{\circ} \mathrm{C}\right)$ & 25 & 24.4 & 53 & 57 & 43 \\
\hline Autoignition temperature $\left({ }^{\circ} \mathrm{C}\right)$ & 463 & 435 & NA & NA & NA \\
\hline Solubility in water at $20^{\circ} \mathrm{C}$ (wt.\%) & 0.7 & 0.5 & Insoluble & Soluble & 0.4 \\
\hline
\end{tabular}

*The register number assigned by the Chemical Abstracts Service as a unique identifier for the compound.

Note: NA: data not available.

alcoholic beverages (e.g. Martinis, daiquiris). It is also used as a solvent in perfumery products and as a plasticizer for cellulose. In industrial applications, it is one of the cheapest chemicals, a fact which contributes to its popularity.

$n$-Propyl propionate, like most FAEs, has a distinctly fruity odor, which may be described as chemically tinged pineapple. In industry, it is used mainly as a polymerization solvent in automotive finishes and coatings, and in printing inks.

$n$-Butyl butyrate (also known as butyl butanoate) is a liquid with a sweet-fruity odor. It is a naturally occurring volatile constituent of many fruits including apples, bananas, berries, pears, plums and strawberries and is also found in honey. It is used in the flavor industry to create sweetfruity flavors.

n-Amyl butyrate (also known as pentyl butyrate or pentylbutanoate) is reminiscent of pear or apricot, and is used in flavorings, as a solvent and plasticizer, and in perfumes.

Hexyl acetate is a liquid with a sweet-fruity, pear-like odor. It is naturally present in a number of fruits and alcoholic beverages. It finds use in fruit-aroma compositions and as a solvent for resins, polymers, fats and oils.

\section{DENSITY-VISCOSITY TESTING}

The density of these selected low-molecular-weight FAEs was measured by direct-reading hydrometer with an accuracy of $1 \mathrm{~kg} \mathrm{~m}^{-3}$. Tests showed that the density-temperature relationship is linear (Fig. 1; Table 2). At a temperature of $-30^{\circ} \mathrm{C}$, the density of the tested liquids lies in the range $911-933.5 \mathrm{~kg} \mathrm{~m}^{-3}$. Of the selected low-molecular-weight

Table 2. Experimental density-temperature equations of selected low-molecular-weight FAEs in temperature range -60 to $+10^{\circ} \mathrm{C}$ $\left(R^{2}>0.999\right)$

\begin{tabular}{ll}
\hline Fluid type & Density $\left(\mathrm{kg} \mathrm{m}^{-3}\right)$ vs temperature $\left({ }^{\circ} \mathrm{C}\right)$ \\
\hline Ethyl butyrate & $\rho=-1.013 t+899.9$ \\
$n$-Propyl propionate & $\rho=-1.015 t+903.1$ \\
$n$-Butyl butyrate & $\rho=-0.910 t+887.7$ \\
$n$-Amyl butyrate & $\rho=-0.876 t+884.4$ \\
Hexyl acetate & $\rho=-0.908 t+890.9$
\end{tabular}

FAEs, n-propyl propionate has the highest density and $n$-amyl butyrate the lowest. The density-temperature relationship for ethyl butyrate is similar to that for $n$-butyl acetate, previously used as a low-temperature drilling fluid. $n$-Propyl propionate and ethyl butyrate best meet the density requirements for deep ice coring in central Antarctica. The density of other tested FAEs is slightly less than required, and these compounds may find application as drilling fluids in cold or very cold ice (i.e. where plastic creep is slow), or for rapid-access drilling projects (i.e. when the project schedule limits closure time).

The viscosity of low-molecular-weight FAEs was measured using a rotational viscometer of DC-6506 type (Fangrui Instrument Co Ltd) with an imbedded thermostat that can maintain temperature in the range -65 to $100^{\circ} \mathrm{C}$. The viscosities of tested FAEs are similar at room temperature, but increase at different rates with decreasing temperature (Fig. 2). All tested FAEs meet the viscosity requirements and do not exceed $16 \mathrm{mPa}$ s. $n$-Amyl butyrate and hexyl acetate are the most viscous, while ethyl butyrate has essentially the same viscosity as $n$-butyl acetate.

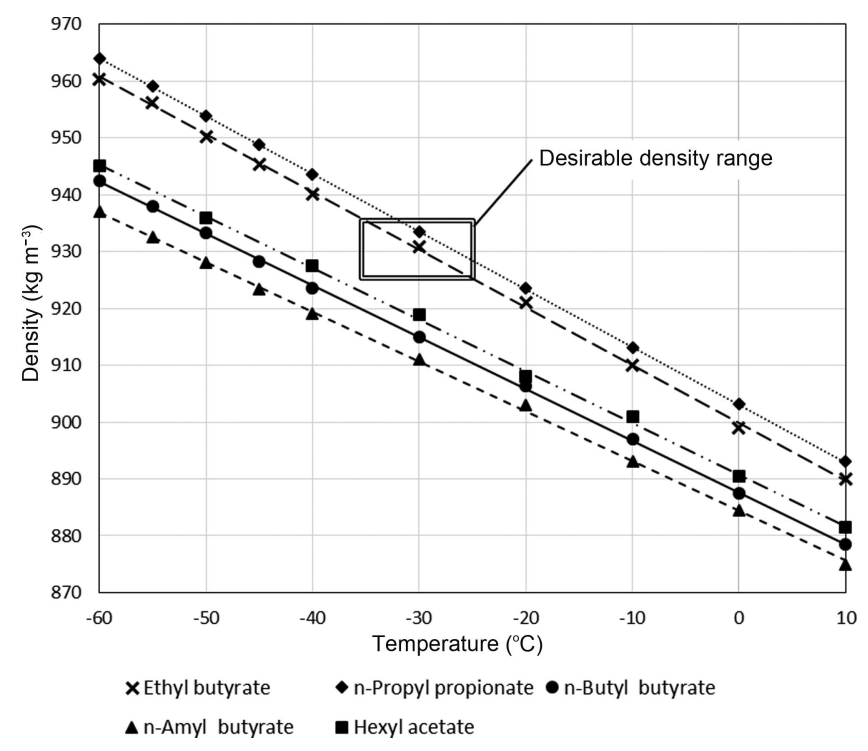

Fig. 1. Density of selected low-molecular-weight FAEs vs temperature. 
Table 3. Experimental viscosity-temperature equations of selected low-molecular-weight FAEs in temperature range -60 to $+10^{\circ} \mathrm{C}$ $\left(R^{2}>0.99\right)$

Fluid type

Dynamic viscosity (mPa s) vs temperature $\left({ }^{\circ} \mathrm{C}\right)$

$\begin{array}{ll}\text { Ethyl butyrate } & \lg \lg (\eta+1)=\frac{329.4}{t_{\mathrm{K}}}-1.729 \\ n \text {-Propyl propionate } & \lg \lg (\eta+1)=\frac{302.8}{t_{\mathrm{K}}}-1.529 \\ n \text {-Butyl butyrate } & \lg \lg (\eta+1)=\frac{375.1}{t_{\mathrm{K}}}-1.761 \\ n \text {-Amyl butyrate } & \lg \lg (\eta+1)=\frac{332.5}{t_{\mathrm{K}}}-1.494 \\ \text { Hexyl acetate } & \lg \lg (\eta+1)=\frac{418.1}{t_{\mathrm{K}}}-1.889\end{array}$

The viscosity-temperature functional connection of the most organic liquids can be linearized by the doublelogarithmic equation (Talalay and Gundestrup, 1999)

$$
\lg \lg (\eta+1)=\frac{A}{t_{\mathrm{K}}}-B,
$$

where $\eta$ is the dynamic viscosity (mPas), $t_{\mathrm{K}}$ is the temperature (K) and $A$ and $B$ are empirical coefficients.

This assumption was again confirmed by experiment, with the viscosity of FAEs fitting the double-logarithmic function with a high coefficient of determination. Applying the equations presented in Table 3, the dynamic viscosity of FAEs can be predicted at any desired temperature. Tests showed that all FAEs are inter-miscible and the resulting density or viscosity can be adjusted within ranges of the end members by proportional mixing of the components.

\section{OTHER TECHNICAL PROPERTIES}

Tested FAEs are clear, colorless liquids with high electrical resistivity (typically $>1000 \mathrm{M} \Omega$ ). The freezing point of testing FAEs lies in the range -73.2 to $-93.3^{\circ} \mathrm{C}$, sufficient to ensure they remain liquid not only in the hole but also during storage outside the drilling shelter.

FAEs are strong solvents, so attention must be paid to the choice of materials for gaskets and electrical insulation (plastic jacket of wire, insulation of electrical sockets, etc.) so as to avoid swelling, softening or other symptoms of degradation. O-rings made from EPDM and Viton ${ }^{\circledR}$ can be used in aggressive chemicals like FAEs with minor effect. Polypropylene, Teflon, polyethylene and nylon are recommended materials as they can withstand extended exposure to esters.

FAEs are soluble in non-polar solvents such as propylene glycol, paraffin oil, ethanol, diethyl ether, and kerosene. FAEs are generally hydrophobic. The tested FAEs are essentially insoluble in water (solubility $<0.7 \%$ ), with the exception of $n$-amyl butyrate. This chemical is most likely to be reactive with ice at subzero temperatures, and might dissolve cuttings and borehole walls.

The higher the vapor pressure of a liquid, the higher the volatility. Ethyl butyrate and n-propyl propionate are highly volatile substances with vapor pressure 1.2 times higher than that of $n$-butyl acetate. Other tested FAEs evaporate relatively slowly.

FAEs present a fire hazard at room temperature, but at temperatures below $0^{\circ} \mathrm{C}$ the fire hazard is quite low. Ethyl butyrate and $n$-propyl propionate are flammable and therefore present on the Special Health Hazard Substance List. Even so, the flash points of these chemicals are higher than that of $n$-butyl acetate $\left(22^{\circ} \mathrm{C}\right)$ and ethanol $\left(12^{\circ} \mathrm{C}\right)$.

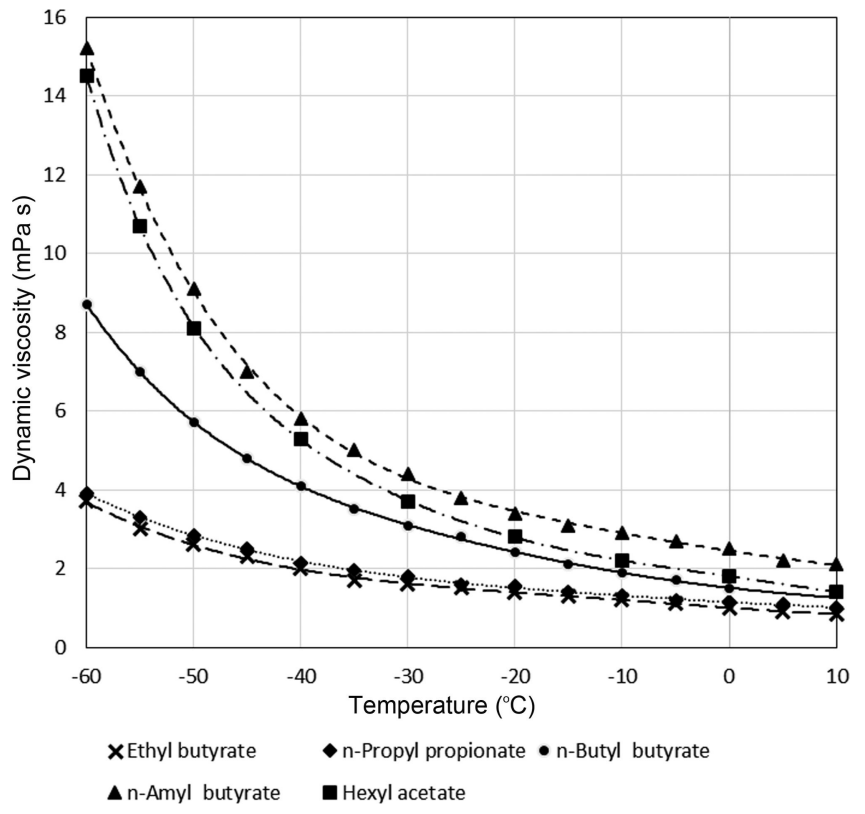

Fig. 2. Viscosity of selected low-molecular-weight FAEs vs temperature.

None of the tested low-molecular-weight FAEs presents a significant health hazard; no occupational exposure limits have been established. All these materials can irritate the skin, and their vapors can irritate the eyes, nose and throat. Standard industrial hygiene (e.g. the use of chemicalresistant gloves) is indicated when handling FAEs, and prolonged skin contact should be avoided. Low-molecularweight FAEs have a strong aroma and their odor-perception thresholds are quite low (>0.015 ppm), so the working area should be well ventilated to prevent workers from being overcome by the odor.

The price of low-molecular-weight FAEs depends, of course, on the type, the customer's ability to negotiate the price, and the volume purchased. The retail price is typically US\$3 to US\$6 $\mathrm{kg}^{-1}$.

\section{CONCLUSIONS}

Preliminary tests indicate that low-molecular-weight FAEs are applicable as drilling fluids in central Antarctica. According to the published data, they are not hazardous to man or animals, and, for this reason, permissible exposure levels in indoor air of work areas are not specified. Most of them are commonly used as fragrance and flavor additives and, when consumed in those concentrations, are harmless to human health.

From the desired-density point of view, ethyl butyrate and $n$-propyl propionate best meet cold-ice drilling requirements. The viscosities of these two chemicals are the lowest among studied FAEs, and do not exceed $4 \mathrm{mPas}$ at temperatures down to $-60^{\circ} \mathrm{C}$. Both are highly volatile substances and essentially insoluble in water. The final disposition regarding the applicability of FAEs to deep, coldice drilling can be made only after field experiments in one or more test boreholes.

\section{ACKNOWLEDGEMENTS}

This research was supported by the National Science Foundation of China (Projects No. 41276189 and No. 41327804) 
and the Ministry of Land and Resources of China (Project No. 201311041). We thank Michael Gerasimoff for editing the paper.

\section{REFERENCES}

Gerasimoff M (2003) Drilling fluid observations and recommendations for U.S. Polar Program, Waiscores Drilling Project. (Internal Report) Space Science and Engineering Center, University of Wisconsin-Madison, Madison, WI http://icedrill. org/Documents/Download.pm?DOCUMENT_ID=50

King JC and Turner J (1997) Antarctic meteorology and climatology. Cambridge University Press, Cambridge

Sheldon S, Steffensen JP, Hansen S, Popp T and Johnsen S (2014) The investigation and experience of using ESTISOL 240 and COASOL as ice core drilling liquids. Ann. Glaciol., 55(68)

Surburg H and Panten J (2006) Common fragrance and flavor materials: preparation, properties and uses, 5th edn. Wiley$\mathrm{VCH}$, Weinheim
Talalay PG (2007) Dimethyl siloxane oils as an alternative borehole fluid. Ann. Glaciol., 47, 82-88 (doi: 10.3189/ 172756407786857785)

Talalay PG and Gundestrup NS (1999) Hole fluids for deep ice core drilling: a review. University of Copenhagen, Copenhagen, 16-65 (doi: 10.2312/report_icedrill)

Talalay PG and Gundestrup NS (2002) Hole fluids for deep ice core drilling. Mem. Natl Inst. Polar Res., Special Issue 56, 148-170

Talalay P and 6 others (2014a) Environmental considerations of low-temperature drilling fluids. Ann. Glaciol., 55(65), 31-40 (doi: 10.3189/2014AoG65A226)

Talalay P and 6 others (2014b) Drilling fluid technology in ice sheets: hydrostatic pressure and borehole closure considerations. Cold Reg. Sci. Technol., 98, 47-54 (doi: 10.1016/j. coldregions.2013.10.012)

Tchistyakov VK, Kratilev A, Lipenkov VYa, Balestrieri JPh, Rado C and Petit JR (1994) Behavior of a deep hole drilled in ice at Vostok Station. Mem. Natl Inst. Polar Res., Specal Issue 49, 247-255 